\title{
Determinação dos compostos fenólicos e da capacidade antioxidante de extratos aquosos e etanólicos de Jambolão (Syzygium cumini L.)
}

\author{
VEBER, J. ${ }^{*}$; PETRINI, L.A.1; ANDRADE, L.B.2; SIVIERO, J. 1. \\ ${ }_{1}^{1}$ Centro de Ciências da Saúde, Curso de Nutrição, Universidade de Caxias do Sul (UCS), Rua Francisco Getúlio \\ Vargas, 1130, Petrópolis, Caixa Postal CEP: 95070-560, Caxias do Sul - Brasil. *juli_veber@hotmail.com; \\ 2Laboratório de Biotecnologia Vegetal e Microbiologia Aplicada, Universidade de Caxias do Sul (UCS), Rua \\ Francisco Getúlio Vargas, 1130, Petrópolis, Caixa Postal CEP: 95070-560, Caxias do Sul - Brasil.
}

RESUMO: A espécie Syzygium cumini conhecida como Jambolão é uma das plantas mais utilizadas na medicina popular principalmente no tratamento de febre, estomalgia, gastropatia e diabetes mellitus tipo 2. O rendimento extrativo de compostos bioativos, e mesmo sua propriedade farmacológica, no caso, a capacidade de desativação de radicais livres, são influenciados pelo método e solvente utilizados. No presente estudo foi avaliado o efeito de extração aquosa a quente e a frio, e as extrações hidroalcoólicas em quatro diferentes concentrações de etanol, de folhas e frutos de Jambolão em diferentes estágios de maturação. A quantificação de compostos fenólicos dos extratos foi realizada pelo método de Folin-Ciocalteau, enquanto o método para avaliar a atividade antirradical livre foi realizado através da capacidade de desativação do radical DPPH $\cdot$. As folhas apresentaram maior quantidade de compostos fenólicos totais $\left(237,52 \mathrm{mg}\right.$. EAG100 $\left.\mathrm{g}^{-1}\right)$ em relação a qualquer dos cinco extratos dos frutos, independente do estágio de maturação destes. Entre os extratos dos frutos, aquele proveniente de frutos verdes apresentou maior quantidade de compostos fenólicos $(109,17 \mathrm{mg}$.EAG100 $\mathrm{g}^{-1}$ ). A extração hidro-etanólica a $50 \%$ de etanol promoveu os maiores conteúdos de fenóis totais, independente do material vegetal. A maior atividade antirradical livre encontrada dentre os extratos mais ricos em fenóis foi obtida com frutos verdes, $I_{50}=2,27 \mathrm{mg} \cdot \mathrm{mL}^{-1}$, a partir da infusão a quente por 30 minutos. Nos extratos de folhas, a maior atividade antirradical livre encontrada foi $I_{50}=23,07 \mathrm{mg} \cdot \mathrm{mL}^{-1}$ proveniente do extrato hidro-etanólico a $50 \%(\mathrm{v} / \mathrm{v})$.

Palavras-Chave: Syzygium cumini, Compostos Fenólicos, Extrato hidro-etanólico, Extrato aquoso, DPPH .

\begin{abstract}
Determination of phenolic compounds and antioxidant capacity of aqueous and ethanolic extracts of Jambul (Syzygium cumini). The species Syzygium cumini, known as Jambul, is one of the most used species in folk medicine because of the possible anti-inflammatory and hypoglycemic activity from its extracts. Studies looking for bioactive compounds in several species have tested many extraction methods evaluating the capacity of sequestration of different types of compounds. In the present study, the effects of hot and cold extraction, as well as hydroalcoholic extraction at four different concentrations were evaluated, using as plant material leaves and fruits at different stages of maturation. The content of phenolic compounds of the obtained extracts was evaluated by the Folin-Ciocalteu method, as well as the antiradical activity by the DPPH $\cdot$ scavenging capacity. Analyzing the five different stages of fruit ripening compared to leaves, it was observed that the leaves had higher averages in the amounts of phenolic compounds (237.52 mg GAE $100 \mathrm{~g}^{-1}$ ) compared to the fruit, being the greenest fruit the one that had the highest amount of phenolic compounds (109.17 mg GAE $100 \mathrm{~g}^{-1}$ ) when compared to the other stages of maturation tested. The extraction using $50 \%$ ethanol showed the best phenol results regardless of the plant material used. The antioxidant activity in the best results for phenols showed a higher antioxidant activity for green fruits $\left(\mathrm{IC}_{50}\right.$ $\left.2.27 \mathrm{mg} \cdot \mathrm{mL}^{-1}\right)$ compared to the leaves $\left(\mathrm{IC}_{50} 23.07 \mathrm{mg} \cdot \mathrm{mL}^{-1}\right)$ regardless of the extract type used.
\end{abstract}

Keywords: Syzygium cumini, phenolic compounds, hydroalcoholic extract, aqueous extract, DPPH.

Recebido para publicação em 13/12/2012 


\section{INTRODUÇÃO}

Syzygium cumini (L.) Skeels, Mirtaceae, é uma árvore com frutos roxos escuros, proveniente da Indomalasia, China e das Antilhas e cultivada em vários países. No Brasil é encontrada em diversos estados das regiões Sudeste, Nordeste e Norte (Migliato et al., 2006; Alberton et al., 2001; Mahmoud et al., 2001; Grover et al., 2001). A composição química das sementes, cascas, folhas, frutos e flores do jambolão têm sido estudada por diversos autores (Sharma et al., 2003; Zanoello et al., 2002; Damasceno et al., 2002; Ahmad \& Beg, 2001; Mahmoud et al., 2001; Nascimento et al., 2000). Análise fitoquímica recente mostrou a presença de fenóis, terpenóides, taninos, saponinas, fitoesteróis, carboidratos, flavonóides e ácidos aminados na casca do caule de S. cumini (Kuncha et al.,2012).

Dados da literatura revelam que é muito mais provável encontrar atividade biológica em plantas orientadas pelo seu uso na medicina popular (etnofarmacologia) do que em plantas escolhidas ao acaso (Migliato et al., 2011).

A casca da árvore, a fruta, as sementes e as folhas desta planta são frequentemente utilizadas na medicina popular para o tratamento de diabetes Mellitus, sendo administrados sob a forma de diferentes preparações, tais como o extrato aquoso ou decocção, o extrato etanólico ou o suco de matéria-prima vegetal, enquanto os frutos são consumidos frescos (Agra et al., 2008; . Leitão et al., 2009). Estudos mostrando atividades carminativa, diurética, anti-inflamatória, antifúngica, entre outras de diferentes partes da planta têm sido relatados na literatura (Ayyanar et al., 2012; Saravanan \& Pari, 2008).

A presença de ácido gálico, derivados do ácido elágico, taninos e flavonóides glicosilados têm sido relatada em espécies de Syzygium cumini (Lima et al., 2007). Ramirez \& Roa Jr (2003) mostraram uma correlação entre a atividade anti-inflamatória e o conteúdo de compostos fenólicos total de extratos de Jambolão.

A presença de compostos fenólicos, flavonóides, especialmente no extrato aquoso de folhas de jambolão e sua atividade antiedematogênica justificam o uso de extratos aquosos e infusões da planta na medicina popular (Lima et al., 2007).

As partes comestíveis de jambolão podem ser consideradas uma excelente fonte de antioxidantes e podem ser incluídas no ranking das frutas com maior potencial nutracêutico (Brandão et al., 2011).

O ensaio Folin-Ciocalteu (Singleton et al., 1999) é um dos mais antigos métodos de quantificação de fenóis em uma amostra, portanto também conhecido como ensaio de fenóis totais.
Apesar da química do Folin-Ciocalteu ainda não estar bem definida, o ensaio de fenóis totais por esse método são convenientes, simples e reprodutivos. Como resultado, uma grande massa de dados estão sendo acumulados através deste e está se tornando um ensaio rotineiro no estudo de antioxidantes fenólicos, uma vez que se estabeleceu uma correlação entre o conteúdo fenólico e a capacidade antioxidante de produtos naturais (Jayaprakasha et al., 2007; Atoui et al., 2005; Picinneli et al., 2004; Anagnostopoulou et al., 2006; Surveswaran et al., 2007; Stratil et al., 2006; Salvador et al., 2006; Termentzi et al., 2006).

Alguns autores recomendam a utilização do método DPPH• por ser um recurso fácil e preciso para a avaliação da atividade antioxidante de produtos naturais (Anagnostopoulou et al., 2006; Atoui et al., 2005; Ribeiro et al., 2002; Cardoso et al., 2005; Stratil et al., 2006; Surveswaran et al., 2007; Jayaprakasha et al., 2007; Termentzi et al., 2006; Aaby et. al., 2004).

Nesse contexto, este trabalho teve como objetivo utilizar essas duas metodologias para determinar e quantificar os compostos fenólicos e relacionar a atividade antirradical livre em extratos aquosos e etanólicos dos frutos em diferentes estágios de maturação e de folhas de Jambolão (Syzygium cumini) coletados no Rio Grande do Sul, buscando estimular futuros estudos científicos nessa espécie que possam promover o cultivo e uso seguro de Syzygium cumini na medicina popular e indústria farmacêutica.

\section{MATERIAL E MÉTODO}

Frutos em cinco diferentes estágios de maturação (verde; verde-arroxeado, arroxeadoesverdeado, meio maduro e totalmente maduro) e folhas foram coletados na Região Serrana do Rio Grande do Sul no mês de abril de 2012. As amostras, em triplicata, foram enviadas ao Herbário do Museu de Ciências Naturais da Universidade de Caxias do Sul (MUCS-UCS). A espécie Syzygium cumini está sob o número de registro 34785 . O material botânico foi levado ao laboratório de Biotecnologia Vegetal e Microbiologia Aplicada da Universidade de Caxias do Sul (UCS), onde foi lavado com água corrente para retirada de resíduos, seco à temperatura ambiente e depois separado e pesado para determinação do peso fresco. As amostras foram submetidas à secagem em estufa à temperatura de $40^{\circ} \mathrm{C}$ até a estabilização do peso seco. Em seguida, as amostras foram maceradas em cadinhos com nitrogênio líquido, e o extrato foi moído e armazenado em tubos do tipo Falcon de 50 
$\mathrm{mL}$ e mantidos em freezer $\mathrm{a}-20^{\circ} \mathrm{C}$ até o momento do preparo dos extratos.

Extratos aquosos a frio, infusão 15 minutos e 30 minutos de S. cumini foram obtidos misturandose $1 \mathrm{~g}$ de matéria seca em pó de $S$. cumini em $10 \mathrm{~mL}$ de água destilada. Para os extratos hidro-etanólicos $(\mathrm{ETOH})$ foram misturados $1 \mathrm{~g}$ da matéria vegetal nas soluções hidroalcoólicas nas concentrações $25,50,75$ e $95 \%$ (v/v). Os sete diferentes tipos de extratos foram armazenados em tubos Falcon de $50 \mathrm{~mL}$. Após foram centrifugados por 15 minutos em centrífuga refrigerada Eppendorf $5804 \mathrm{R}$ a $4{ }^{\circ} \mathrm{C}$ sob rotação de $11.000 \mathrm{rpm}$. Em seguida, foi retirado o sobrenadante e aliquotado em eppendorfes de 2 $\mathrm{mL}$ e armazenados $\mathrm{a}-20^{\circ} \mathrm{C}$ até a execução dos ensaios.

Os extratos a frio permaneceram em repouso por $24 \mathrm{~h}$ protegidos da luz, com o propósito de extrair os compostos hidrossolúveis (Torres et al., 2001). As amostras de infusão foram submetidas a dois diferentes tempos de aquecimento (15 e 30 minutos) em Banho-Maria CT-248 (CIENTEC) a $80^{\circ} \mathrm{C}$, metodologia descrita por Stein et al. (2005). Para a preparação dos extratos hidroalcoólicos de S. cumini, os mesmos foram aquecidos em banhomaria a $70{ }^{\circ} \mathrm{C}$ durante 30 minutos, metodologia descrita por Asolini et al. (2006).

Para a quantificação dos compostos fenólicos de S. cumini foi utilizado o método de FolinCiocalteau modificado por Roesler et al. (2007), onde foram utilizados extratos na proporção de 1:10 (p/v). O processo de quantificação foi minimizado a escala de volume total de $1,0 \mathrm{~mL}$. Dessa solução foram coletados $100 \mu \mathrm{L}$ do extrato, acrescidos de $500 \mu \mathrm{L}$ do reagente de Folin-Ciocalteau e $400 \mu \mathrm{L}$ de carbonato de sódio a $7.5 \%$. As amostras foram agitadas em agitador de soluções AP56 (Phoenix), incubadas por
5 min a $50^{\circ} \mathrm{C}$, resfriadas a temperatura ambiente $\left(25^{\circ} \mathrm{C}\right)$. A absorbância $(\mathrm{Aa})$ da fração líquida foi determinada a $760 \mathrm{~nm}$ em espectrofotômetro Biochrom Libra S12. Curva de calibração de ácido gálico foi utilizada para quantificação dos fenóis totais (Figura 1). Os resultados foram expressos em equivalentes de ácido gálico (mg EAG.100 g-1).

Para a avaliação da atividade antirradical livre dos extratos totais pela desativação do radical livre DPPH (2,2-difenil-1-picrilhidrazila) de extratos de $S$. cumini foram utilizados extratos de folhas e frutos de $S$. cumini os quais foram avaliados quanto a sua capacidade em doar hidrogênio para DPPH• de acordo com Yamaguchi et al. (1998). Para tanto, $200 \mu \mathrm{L}$ das soluções dos diferentes extratos, diluídos em água destilada foram misturados com $800 \mu \mathrm{L}$ de uma solução tampão Tris- $\mathrm{HCl} 100$ mM, pH 7,0. A essa mistura, foram adicionados $1000 \mu \mathrm{L}$ da solução etanólica de DPPH• $500 \mu \mathrm{M}$ (Sigma Chem. Co.) e os tubos foram mantidos por 20 minutos ao abrigo da luz. A medida de absorbância foi feita em espectrofotômetro UV-visível a $517 \mathrm{~nm}$. Nos controles, as amostras das soluções dos diferentes extratos foram substituídas por água destilada. A medida da absorbância do branco corresponde à concentração de DPPH• da solução $(250 \mu \mathrm{M})$. Foram realizadas, no mínimo, duas repetições e o resultado foi expresso como capacidade de desativação de do radical $\mathrm{DPPH} \cdot \mathrm{e}$ em $\mathrm{IC}_{50}$, ou seja, a quantidade de extrato necessária para reduzir $50 \%$ do radical livre DPPH.

Cálculo:

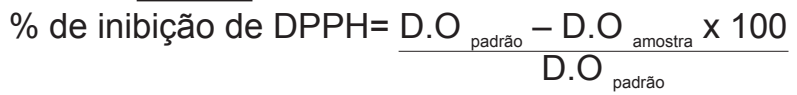

Todas as determinações analisadas estatisticamente foram efetuadas em triplicata e os

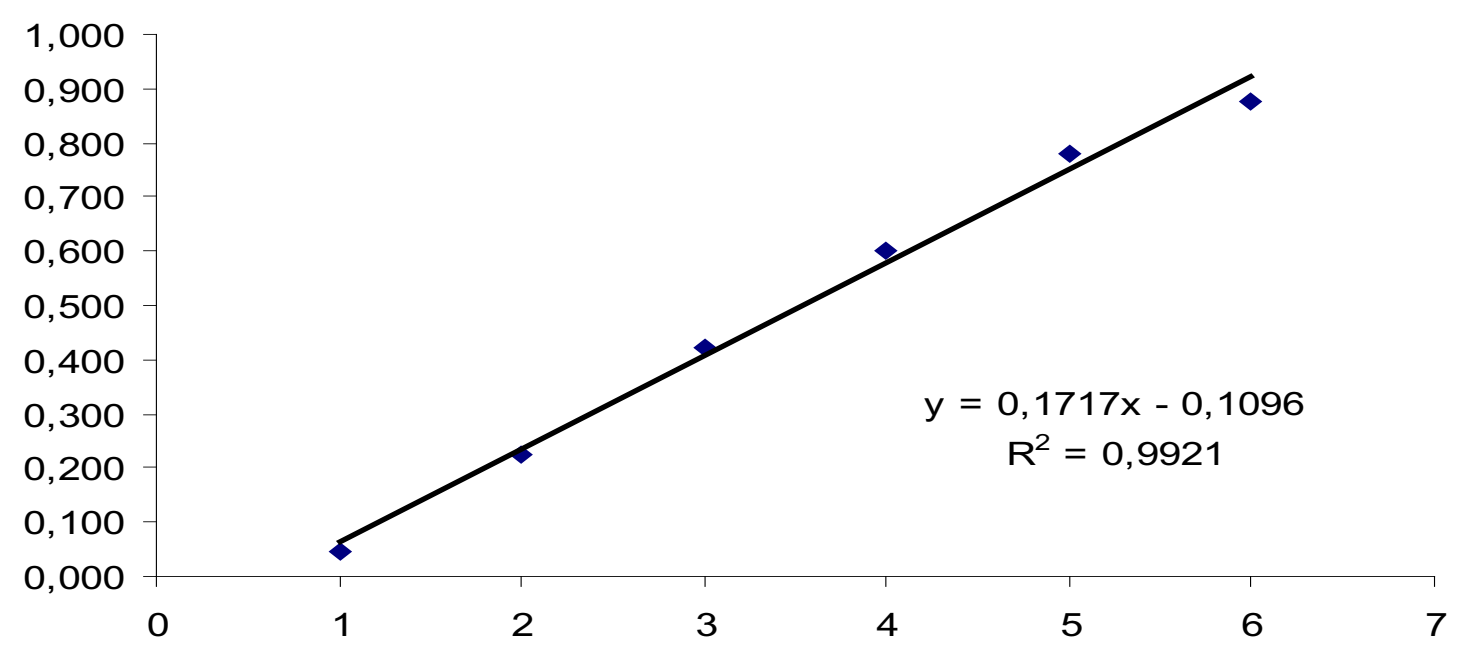

FIGURA1. Curva padrão de ácido gálico a 760 nm (Folin-Ciocalteau) em D.O. utilizada para compostos fenólicos com equação da reta com valor $R^{2}=0,9921$. 
resultados submetidos à análise de variância e teste de Tukey ao nível de $5 \%$ de probabilidade utilizando programa computacional SPSS ${ }^{\circledR}$ (Statistical Package for the Social Sciences) vs.17.0.

\section{RESULTADOS E DISCUSSÃO}

Os resultados da quantificação dos compostos fenólicos dos extratos das folhas e frutos de Syzygium cumini nos diferentes tipos de extratos (aquosos e hidroalcoólicos) e estágios de maturação estão discriminados nas Figuras 2 e 3.

Avaliando os sete diferentes tipos de extratos quanto aos compostos fenólicos, observou- se que o extrato hidro-etanólico $50 \%$ (v/v) destacouse com 221,03 mg EAG $100 \mathrm{~g}^{-1}$, sendo seguido pelo extrato hidro-etanólico $25 \%$ (v/v) com 122,82 mg EAG $100 \mathrm{~g}^{-1}$ e o extrato aquoso de infusão 30 minutos com 99,86 mg EAG $100 \mathrm{~g} \mathrm{~g}^{-1}$. O extrato a frio (87,38 mg EAG $\left.100 \mathrm{~g} \mathrm{~g}^{-1}\right)$ e o extrato hidro-etanólico $75 \%$ (96,12 mg EAG $\left.100 \mathrm{~g}^{-1}\right)$ não apresentaram diferença significativa. Os extratos de infusão 15 minutos com 82,45 mg EAG $100 \mathrm{~g}^{-1} \mathrm{e}$ o extrato hidroalcoólico $95 \%$ apresentaram os menores índices de compostos fenólicos (Figura 2).

Analisando os cinco diferentes estágios de maturação dos frutos comparados as folhas, observou-se que as folhas apresentaram as

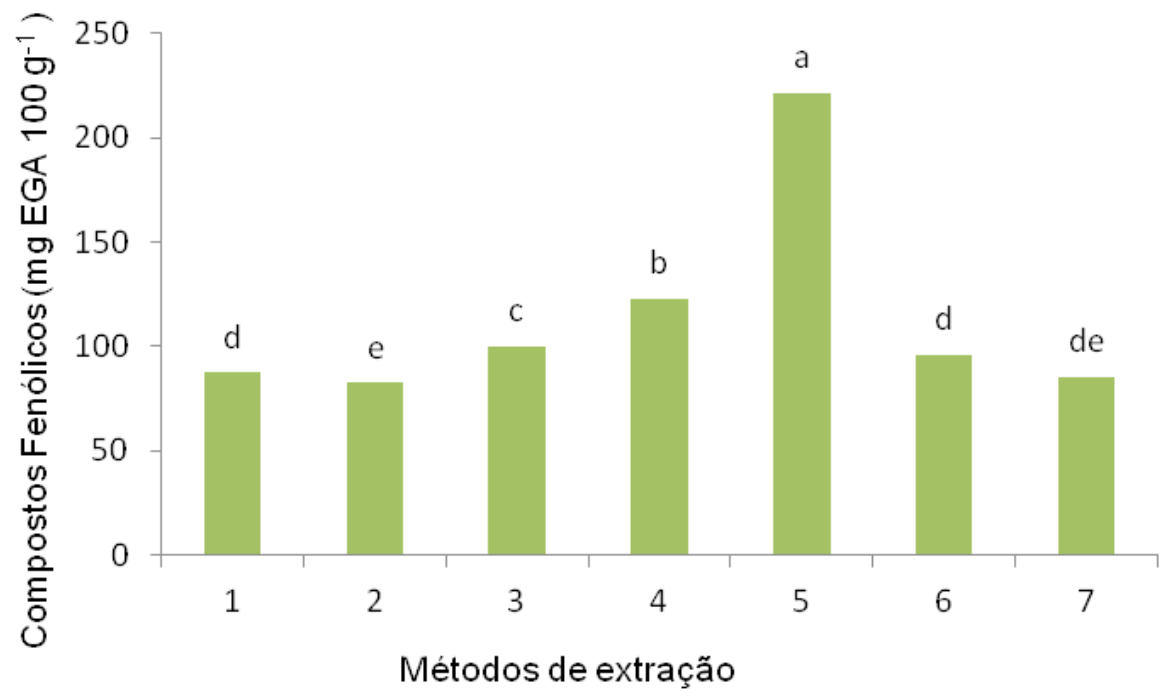

FIGURA 2. Conteúdo fenólico de folhas e frutos de S.cumini conforme os tipos de extratos. Extrato a frio (1), extrato infusão 15 minutos (2), extrato infusão 30 minutos (3), extrato hidro-etanólico $25 \%$ (4), extrato hidroetanólico 50\% (5), extrato hidro-etanólico $75 \%$ (6), extrato hidro-etanólico 95\% (7). Letras distintas entre os tratamentos diferem significativamente pelo teste de Tukey $(p \geq 0,05)$.

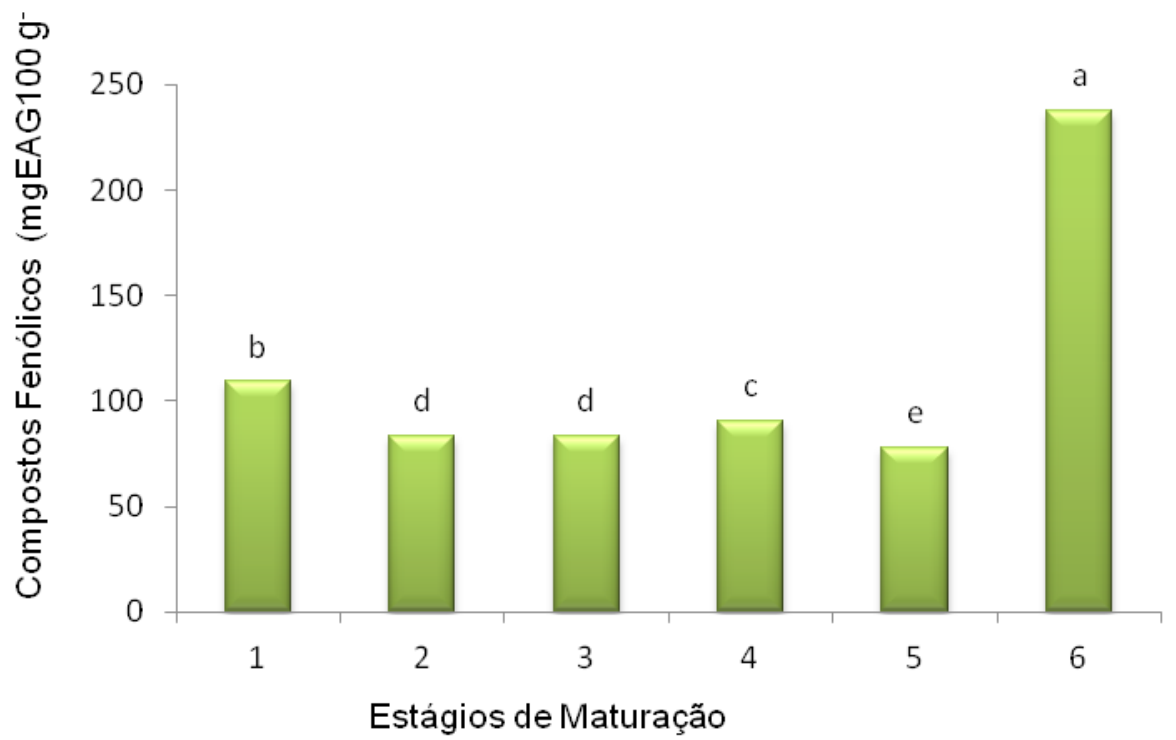

FIGURA 3. Conteúdo fenólico de folhas e frutos de S. cumini conforme os estágios de maturação. Frutos verdes (1), frutos verdes-arroxeados (2), frutos arroxeados-esverdeado (3), frutos meio maduros (4), frutos totalmente maduros (5), folhas (6). Letras distintas entre os tratamentos diferem significativamente pelo teste de Tukey $(p \geq 0,05)$. 
maiores médias com cerca de 237,52 mg EAG 100 $\mathrm{g}^{-1}$ apresentando maior quantidade de compostos fenólicos em relação ao estágio de maturação verde $\left(109,17 \mathrm{mg}^{\mathrm{EAG}} 100 \mathrm{~g} \mathrm{~g}^{-1}\right)$ que foi o maior índice encontrado entre os frutos de jambolão avaliados.

Brandão et al. (2011) quantificando compostos fenólicos em frutos de jambolão pelo método de Folin Ciocalteau também encontraram quantidades maiores de compostos fenólicos em frutos imaturos e afirmaram que a diminuição de compostos fenólicos indicam maturidade apresentando resultados semelhantes ao presente estudo.

A composição química depende da espécie, condições ambientais, e também sobre o estádio de maturação do fruto (Vendramini \& Trugo, 2000), no entanto, ainda não se sabe muito sobre a bioquímica, estrutural e alterações fisiológicas envolvidas neste processo (Awad,1993; Medeiros \& Raseira, 1998; Figueiredo et al., 2001; Chitarra \& Chitarra, 2005).

Independente do tratamento realizado nos extratos de S. cumini pode-se observar na Figura 4 que o extrato de folhas apresentou os maiores resultados de compostos fenólicos em relação aos demais tipos de extratos testados. Lembrando novamente que o extrato hidro-etanólico $50 \%$ (v/v) foi o que apresentou maiores índices de compostos fenólicos para folhas e para todos os diferentes estágios de maturação dos frutos avaliados no presente estudo.

A diminuição do teor de compostos fenólicos em S. cumini pode estar relacionado com uma série de acontecimentos genéticos que se correlacionam com um sistema complexo de envelhecimento que regula a sua natureza e da abundância de metabolitos. Estas incluiriam estímulos internos e externos tais como taxa de luminosidade, índices pluviométricos, estímulos patogênicos e hormonais. (Lima et al., 2007).

Em relação ao tipo de extração seja a frio ou em infusão 15 minutos e 30 minutos não se observaram diferenças significativas quanto a avaliação da quantidade de compostos fenólicos (Figura 2 e 4).

Os resultados obtidos da quantificação dos compostos fenólicos dos extratos a frio estão de acordo com aqueles apresentados por Vizzoto \& Pereira (2011) que buscavam otimização do processo de extração para determinação de compostos fenólicos antioxidantes de amora-preta (Rubus sp.). Esses autores relatam que solventes com alta polaridade, como a água não são bons extratores, afirmando que o uso de água pura resulta em extratos com alta impureza (ácidos orgânicos, açúcares, proteínas solúveis), podendo interferir na quantificação dos compostos fenólicos.

Os extratos que apresentaram os maiores índices para compostos fenólicos foram selecionados para avaliação quanto a sua atividade antirradical livre. $O$ extrato aquoso infusão em 30 minutos e hidro-etanólicos 25 e $50 \%(\mathrm{v} / \mathrm{v})$ de folhas e frutos verdes de $S$. cumini então foram escolhidos para ensaio de determinação da desativação do radical DPPH $\cdot$. Os resultados estão apresentados na Tabela 1 indicando que os frutos apresentaram maiores

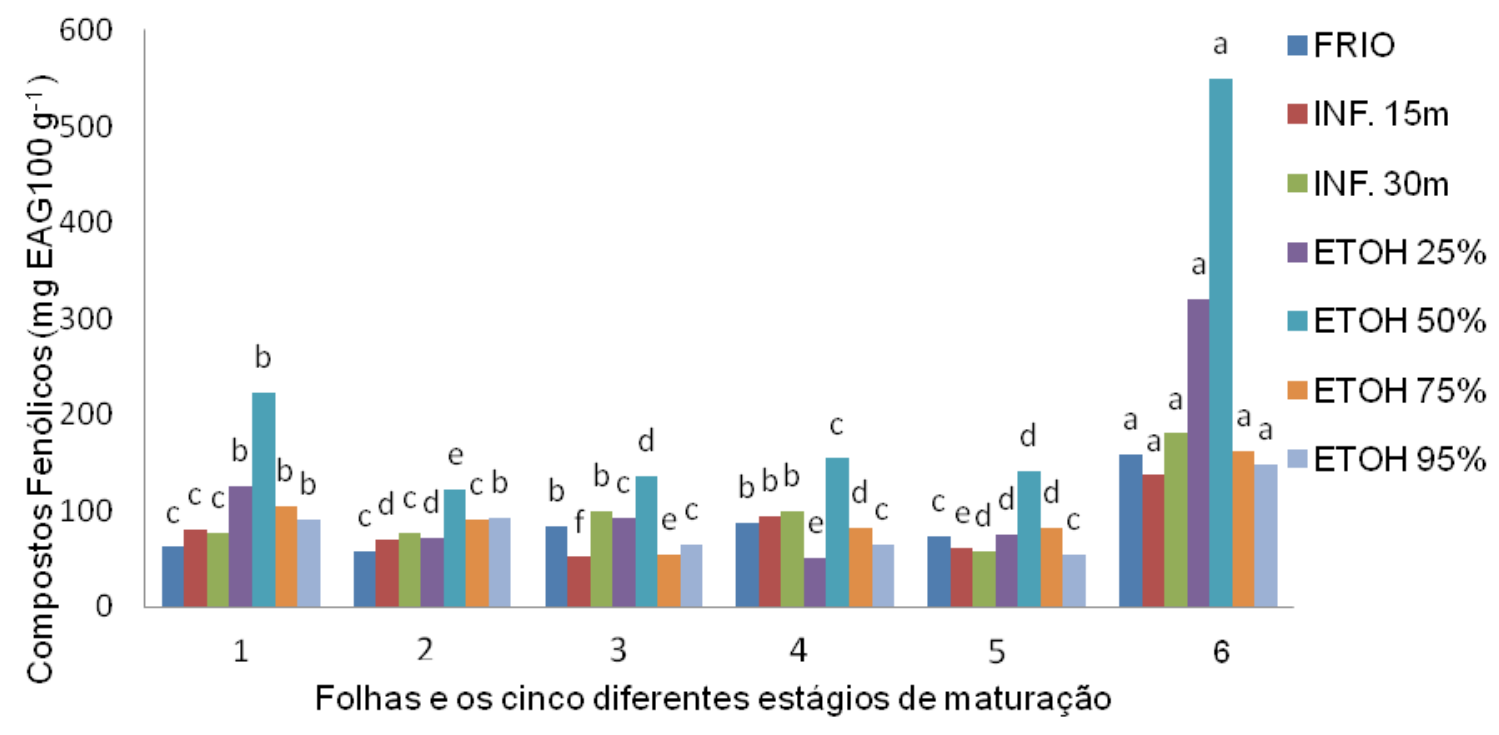

FIGURA 4. Comparação do conteúdo fenólico das folhas e frutos de S. cumini conforme os tipos de extratos e estágios de maturação. Frutos verdes (1), frutos verdes-arroxeados (2), frutos arroxeados-esverdeado (3), frutos meio maduros (4), frutos totalmente maduros (5), folhas (6). ETOH = Extrato hidro-etanólico. Letras distintas entre os tratamentos diferem significativamente pelo teste de Tukey $(p \geq 0,05)$. 
TABELA 1. Percentual de redução do radical DPPH•e valor de $\mathrm{IC}_{50}{ }^{*} \pm$ desvio padrão para os extratos aquosos e hidro-etanólicos de folhas e frutos verdes de S. cumini.

\begin{tabular}{cccc}
\hline & \multicolumn{3}{c}{ Métodos de extração } \\
\cline { 2 - 4 } DPPH $\left(\mathbf{I C}_{50}\right)$ & Infusão por $\mathbf{3 0}$ min & Etanol $\mathbf{2 5 \%}$ & Etanol $\mathbf{5 0 \%}$ \\
\hline Extratos de Folhas & $56,09 \pm 0,05$ & $32,92 \pm 1,20$ & $23,07 \pm 0,39$ \\
Extratos de Frutos verdes & $2,27 \pm 0,09$ & $2,93 \pm 0,54$ & $3,75 \pm 0,23$ \\
\hline
\end{tabular}

${ }^{*} \mathrm{IC}_{50}$ - quantidade de amostra necessária para desativação de $50 \%$ do radical $\mathrm{DPPH} \bullet$

atividades antirradical livre em relação as folhas, independente do tipo de extração realizada.

Diferenças entre a capacidade antirradical livre em relação ao tipo de extrato utilizado ficam mais claras nos extratos de folhas quando comparados aos frutos verdes mostrando maior atividade no extrato hidro-etanólico $50 \%$ (v/v) com $\mathrm{IC}_{50} 23,07 \pm 0,39 \mathrm{mg} \cdot \mathrm{mL}^{-1}$ seguidos do extrato hidroetanólico $25 \%(\mathrm{v} / \mathrm{v}) \mathrm{com} \mathrm{IC}_{50} 32,92 \pm 0,39 \mathrm{mg} \cdot \mathrm{mL}^{-1}$ e do extrato de infusão 30 minutos.

\section{CONCLUSÃO}

Com base nos resultados obtidos no presente trabalho, pode-se concluir que para os extratos e tipos de testes realizados, as folhas de S.cumini apresentaram maior presença de compostos fenólicos quando comparadas aos cinco diferentes estágios de maturação do fruto e em relação aos métodos de extração empregados, destacamos o extrato hidro-etanólico $50 \%(\mathrm{v} / \mathrm{v})$. A capacidade antirradical livre dos melhores resultados obtidos para compostos fenólicos revelaram diferenças nas fontes de compostos bioativos presentes nas folhas e frutos. Maiores estudos necessitam ser realizados para a elucidação desse mecanismo complexo de capacidade antioxidante de S. cumini.

\section{REFERÊNCIAS}

AABY, K., HVATTUM, E., SKREDE, G. Analysis of flavonoids and other phenolic compounds using highperformance liquid chromatography with coulometric array detection: Relationship to antioxidant activity Journal of Agricultural and Food Chemistry. V.52, p.4595-4603, 2004.

AGRA, M.F, et al. Survey of medicinal plants used in the region Northeast of Brazil. Revista Brasileira de Farmacognosia, v.18, n.3, pp.472-508, 2008.

AHMAD, I.; BEG, A.Z. Antimicrobial and phytochemical studies on 45 Indian medicinal plants against multidrug resistant human pathogens. Journal of Ethnopharmacology, v. 74, pp. 113-123, 2001.

ALBERTON, J.R, et al. Caracterização farmacognóstica do jambolão (Syzygium cumini (L.) Skeels). Revista Brasileira de Farmacognosia, v.11, pp. 3750, 2001.

ANAGNOSTOPOULOU, M.A. et al. Radical scavenging activity of various extracts and fractions of sweet orange peel (Citrus sinensis). Food Chemistry V.94, p.19-25, 2006.
ASOLINI, F.C, et. al. Atividade Antioxidante e Antibacteriana dos compostos Fenólicos dos Extratos de Plantas Usadas como Chás. Journal of Food Technology Preprint, Serie, n. 252, pp.209-215, 2006.

ATOUI, A.K. et. al. Tea and herbal infusions: Their antioxidant activity and phenolic profile. Food Chemistry V.89 p.27-36, 2005.

AWAD, M. Fisiologia pós-colheita de frutos. São Paulo: Nobel, 1993.

AYYANAR, M.; SUBASH-BABU, P. Syzygium cumini (L.) Skeels: A review of its phytochemical constituents and traditional uses. Asian Pacific Journal of Tropical Biomedicine, v. 2, pp. 240 - 246, 2012.

BRANDÃO, T.S.O de, et al. Changes in enzymes, phenolic compounds, tannins, and vitamin $C$ in various stages of jambolan (Syzygium cumini Lamark) development. Ciência e Tecnologia de Alimentos, vol.31, n.4, pp. 849-855, 2011.

CARDOSO, C.L., et al. New Biflavonoid and Other Flavonoids from the Leaves of Chimarrhis turbinata and their Antioxidant Activities. Journal of the Brazilian Chemical Society, V.15, 2005.

CHITARRA, M. I. F.; CHITARRA, A. B. Pós-colheita de frutos e hortaliças: fisiologia e manuseio. 2. ed. Lavras: UFLA, 2005.

DAMASCENO, D.C, et al. Avaliação do efeito hipoglicemiante da sapogenina extraída de sementes de Eugenia jambolana Lam. Revista Brasileira de Plantas Medicinais, v. 4, pp. $46-54,2002$.

FIGUEIREDO, R. W. et al. Alterações de firmeza, pectinas e enzimas pectinolíticas durante o desenvolvimento e maturação de pedúnculos de cajueiro anão precoce (Anacardium occidentale L. Var. nanum). Proceedings of the Interamerican Society for Tropical Horticulture, v. 43, p. 82-86, 2001.

GROVER, J.K, et al. Traditional Indian anti-diabetic plants attenuate progression of renal damage in streptozotocin induced diabetic mice. Journal of Ethnopharmacology, v. 76, n.3, pp. $233-238,2001$.

JACQUES, A.C.; ZAMBIAZI, R.C. Fitoquímicos em amorapreta (Rubus spp). Semina: Ciências Agrárias, v. 32, n. 1, pp. 245-260, 2011.

JAYAPRAKASHA, G.K., et al. Antioxidant and antimutagenic activities of Cinnamomum zeylanicum fruit extracts. Journal of Food Composition and Analysis. V.20, p.330-336, 2007.

KUNCHA et al. In vitro evaluation of nitric oxide scavenging activity of methanolic and aqueous extract of Syzygium Cumini Linn. Bark (Myrtaceae). International Journal of Pharmaceutical Sciences, v. 3, pp. $615-619,2012$.

LEITÃO, F, et al. Urban ethnobotany in Petrópolis and Nova Friburgo (Rio de Janeiro, Brazil). Revista

Rev. Bras. PI. Med., Campinas, v.17, n.2, p.267-273, 2015. 
Brasileira de Farmacognosia, v.19, n.1B, pp. 333342, 2009.

LIMA, L.A, et al. Correlation of anti-inflammatory activity with phenolic content in the leaves of syzygium cumini (I.) skeels (myrtaceae). Química Nova, vol.30, n.4, pp. 860-864, 2007.

MAHMOUD, I.I, et al. Acylated fl avonol glycosides from Eugenia jambolana leaves. Phytochemistry, v. 58, pp. 1239-1244, 2001.

MEDEIROS, C. A. B.; RASEIRA, M. C. B. A cultura do pessegueiro. Brasília: Embrapa, 1998.

MIGLIATO, K.F, et al. Ação farmacológica de Syzygium cumini (L.) Skeels. Acta Farmacéutica Bonaerense, vol. 25, pp. 310-314, 2006.

MIGLIATO, K.F, et al. Planejamento experimental na otimização da extração dos frutos de Syzygium cumini (L.) skeels. Química Nova, vol.34, n.4, pp. 695-699, 2011.

NASCIMENTO, G.G.F, et al. Antibacterial activity of plant and phytochemicals on antibiotic resistant bacteria. Brazilian Journal of Microbiology, v. 31, pp. 247-256, 2000.

PICCINELLI, A.L. et al. Phenolic constituents and antioxidant activity of Wendita calysina leaves (burrito), a folk Paraguayan tea. Journal of Agricultural and Food Chemistry. V.52, p.5863-5868, 2004.

RAMIREZ, R.O; ROA JR, C.C. The gastroprotective effect of tannins extracted from duhat (Syzygium cumini Skeels) bark on $\mathrm{HCl} /$ ethanol induced gastric mucosal injury in Sprague-Dawley rats. Journal Clinical Hemorheology and Microcirculation, v. 29, n. 3-4, pp. $253-261,2003$.

RIBEIRO, A.B. et al. Flavonóis glicosilados antioxidantes de Nectandra grandiflora (Lauraceae). Eclética. Química. V.27, 2002.

RICE-EVANS, C.A, et al. Structure-antioxidant activity relationships of flavonoids and phenolic acids. Free Radical Biology \& Medicine, v. 20, pp. 933-956, 1996.

ROESLER, R, et al. Atividade antioxidante de frutas do cerrado. Ciência e Tecnologia de Alimentos, vol.27, n.1, pp. 53-60, 2007.

SALVADOR, M.J. et al. Isolation and HPLC quantitative analysis of antioxidant flavonoids from Alternanthera tenella Colla. Zeitschrift für Naturforschung. V.61. p.19 $-25,2006$

SARAVANAN, G.; PARI, L. Hypoglycaemic and Antihyperglycaemic Effect of Syzygium cumini Bark in Streptozotocin Induced Diabetic Rats. Journal of
Pharmacology and Toxicology, v. 3, pp. 1 - 10, 2008.

SHARMA, S.B, et al. Hypoglycaemic and hypolipidemic effect of ethanolic extract of seeds of Eugenia jambolana in alloxaninduced diabetic rabbits. Journal of Ethnopharmacology, v. 85, pp. 201-206, 2003.

SINGLETON, V.L. et al. Analysis of total phenols and other oxidation substrates and antioxidants by means of Folin-Ciocalteu reagent. Methods Enzymology. V.299, p.152 -178, 1999.

STEIN, A.C, et al. Ethnoveterinary medicine in the search of antimicrobial agents: Antifungal activity of Pterocaulon (Asteraceae). Journal of Ethanopharmacology, v: 99, pp. 211-214, 2005.

STRATIL, P. et al. Determination of Total Content of Phenolic Compounds and Their Antioxidant Activity in Vegetables Evaluation of Spectrophotometric Methods. Journal of Agricultural and Food Chemistry, V.54, p.607-616, 2006.

SURVESWARAN, S. et al. Systematic evaluation of natural phenolic antioxidants from 133 Indian medicinal plants. Food Chemistry V.102, p.938-953, 2007.

TERMENTZI, A. et al. Antioxidant activities of various extracts and fractions of Sorbus domestica fruits at different maturity stages. Food Chemistry V.98, p.599-608, 2006.

TORRES, A.L, et. al. Efeito de extratos aquosos de plantas no desenvolvimento de Plutella xylostella (L.) (Lepidoptera: Plutellidae). Neotropical Entomology, v.30, pp.151-156, 2001.

VENDRAMINI, A. L.; TRUGO, L. C. Chemical composition of acerola fruit (Malpighia punicifolia L.) at three stages of maturity. Food Chemistry, v. 71, p. 195-198, 2000.

VIZZOTTO, M.; PEREIRA, M.C. Amora-preta (Rubus sp.): otimização do processo de extração para determinação de compostos fenólicos antioxidantes. Revista Brasileira de Fruticultura, v. 33, n. 4, pp. 1209-1214, 2011.

YAMAGUCHI, T. et al. HPLC method for evaluation of the free radical - scavenging of foods by using 1.1-diphenyl-2-pycrylhydrazyl. Bioscience, Biotechnology and Biochemistry. v. 62, pp. 12011204, 1998.

ZANOELLO, A.M, et al. Efeito protetor do Syzygium cumini contra Diabetes Mellitus induzido por aloxano em ratos. Acta Farmacêutica Bonaerense, v. 21, pp.31 - 36, 2002. 